University for Business and Technology in Kosovo

UBT Knowledge Center

UBT International Conference

2015 UBT International Conference

Nov 7th, 9:00 AM - 5:00 PM

\title{
The Analytic Hierarchic Process: A Model to Evaluate the Risk of Getting Cancer
}

Daniela (Halidini) Qendraj

Aleksander Moisiu University, daniela_qendraj@hotmail.com

Markela Muca

University of Tirana, markela.moutsa@yahoo.com

Follow this and additional works at: https://knowledgecenter.ubt-uni.net/conference

Part of the Computer Sciences Commons, and the Digital Communications and Networking Commons

\section{Recommended Citation}

Qendraj, Daniela (Halidini) and Muca, Markela, "The Analytic Hierarchic Process: A Model to Evaluate the Risk of Getting Cancer" (2015). UBT International Conference. 86.

https://knowledgecenter.ubt-uni.net/conference/2015/all-events/86

This Event is brought to you for free and open access by the Publication and Journals at UBT Knowledge Center. It has been accepted for inclusion in UBT International Conference by an authorized administrator of UBT Knowledge Center. For more information, please contact knowledge.center@ubt-uni.net. 


\title{
The Analytic Hierarchic Process: A Model to Evaluate the Risk of Getting Cancer
}

\author{
Daniela Qendraj (Halidini)1, Markela $\mathrm{Muca}^{2}$ \\ ${ }^{1}$ Department of Mathematics, Faculty of Information Technology, University \\ “Aleksandër Moisiu” Durrës, Albania. \\ ${ }^{2}$ Department of Mathematics, Faculty of Natural Sciences, UT, Albania. \\ daniela_qendraj@hotmail.com ${ }^{1}$, markela.moutsa@yahoo.com ${ }^{2}$
}

\begin{abstract}
The aim of this study is to classify the risk factors of being with a type of cancer by applying the AHP (analytic hierarchy process) scale. The Saaty's analytic hierarchy process is applied for computing weights for the factors, is a modeling for classification. A case study of QSUT Tirana hospital data base is presented to rank four cancer types. By the data collect from the hospital during the years 2011-2015, the results show that lung cancer is mostly spread in humans, and the prostate cancer is lower spread in humans.
\end{abstract}

Keywords: AHP process, local weights, IC, cancer types.

\section{Introduction}

Now days the most discussions are focused in developing of science in cancer disease. Despite of the long searches, the factors of causing cancer are several and not fixed. Science has concluded that the number of factors that causes cancer depends on the type of cancer. For example nasal carcinoma is caused by smoking, working under poor ventilation, herbal drugs, nasal balms [6]. The most factors leading to cancer are the chemical exposure, family history, alcohol. So, there are no clear evidences to provide specific risk factor to cancer. To classify the factors in cancer disease we have the model of Multiple Criteria Decision Making that is analytic hierarchy process (AHP). The AHP provides a structured problem, to evaluate alternative solutions, and is presented firstly by Thomas Saaty in 1971-1975 [1]. It is used to derive ratio scales from both discrete and continuous paired comparisons. In the discrete case these comparisons leads to dominance matrices and in the continuous case to kernels of Fredholm operators, for which ratio scales are derived in the form of principal eigenvectors.

\section{Analytic Hierarchy Process (AHP)}

The analytic hierarchy process is a tool in multi-criteria decision making which compose the factors in a hierarchic problem structure. The applications are in different research areas especially in the government, health [6], business [7], industry, building and education [4].

At first of the AHP procedures, is the aim of the problem, represented by the decision maker. It considers the first level of the hierarchy, second level are the multiple criteria, the last level are alternatives. The general steps of the AHP model are as follow:

\section{Construct a hierarchy structure for the problem.}


Table 1 Saaty fundamental scale

\begin{tabular}{ll}
\hline $\begin{array}{l}\text { Preference for pair-wise } \\
\text { comparison }\end{array}$ & $\begin{array}{l}\text { Preference } \\
\text { number }\end{array}$ \\
\hline Equally important & 1 \\
Moderately more important & 3 \\
Strongly more important & 5 \\
Very strong more important & 7 \\
Extremely more important & 9 \\
Intermediate value & $2,4,6,8$ \\
\hline
\end{tabular}

2. Rating the importance of the factors using the pair-wise comparison. We write the matrix A to compare each criterion to the others.

$$
A=\left(\begin{array}{cccc}
1 & \omega_{1} / \omega_{2} & \ldots & \omega_{1} / \omega_{n} \\
\omega_{2} / \omega_{1} & 1 & \ldots & \omega_{2} / \omega_{n} \\
\ldots & \ldots & \ldots & \ldots \\
\omega_{n} / \omega_{1} & \omega_{n} / \omega_{2} & \ldots & 1
\end{array}\right)
$$

Find the eigenvector by normalized the pair-wise comparisons. We denote with vector $S$ the sum of the columns of the matrix and Divide each entry by the total of the column. Divide the total of row by the total of number of row. Rate each factor relative to the others, base of degree of risk, for each selected factor. So, doing the pair-wise comparison of the choices.

Normalize the pair-wise comparisons. Calculate index of consistence $I C=\frac{\lambda_{\max }-1}{n-1}$ where $\lambda_{\max }$ is the eigenvalue calculated for all matrix of $n \times n$ dimensions, $\lambda_{\max }=\sum_{i=1,4} \omega_{i} \cdot s_{i}$, si are the sums of each columns of the matrix by $i$.

Table 2 The IC and $\lambda^{*}{ }_{\max }$ limited values for all nxn matrix

\begin{tabular}{ccccccccccc}
\hline $\mathrm{n}$ & 1 & 2 & 3 & 4 & 5 & 6 & 7 & 8 & 9 & 10 \\
\hline $\mathrm{IC}$ & - & - & 0.58 & 0.9 & 1.12 & 1.24 & 1.32 & 1.41 & 1.45 & 1.49 \\
$\lambda^{*}{ }_{\max }$ & - & - & 3.11 & 4.27 & 5.44 & 6.62 & 7.79 & 8.89 & 10.1 & 11.3 \\
& & & & & & & & & & \\
\hline
\end{tabular}

1. Combined step 2 and 4 to obtain a relative rating for each choice.

\section{Real data. Analytic Hierarchic Process.}


This study is focused in the data base of Tirana Hospital, to evaluate the risk of getting cancer based on these factors that are smoke, alcohol, obesity, family history. The data base is obtained during the years 2010-2015, the mostly types of cancer are: throat cancer, lung cancer, breast cancer and prostate cancer. We will construct the hierarchical structure, where the decision maker is considered cancer risk, as the first level of the structure. In the second level are the factors as: smoke, alcohol, obesity, family history. In the third level are cancer types as: throat, lung, breast, prostate. The hierarchical structure is shown on Figure 1.

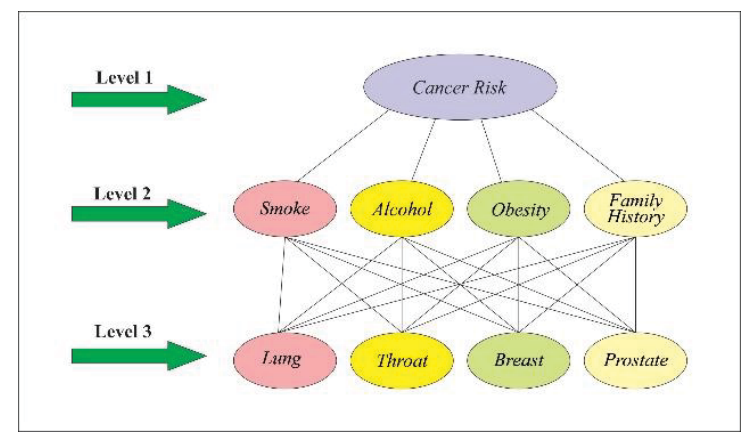

Fig 1. The hierarchical structure of this data set

Table 4. Comparison matrix of the factors in the $2^{\text {nd }}$ level

\begin{tabular}{ccccc}
\hline Risk factors & Smoke & Alcohol & Obesity & $\begin{array}{c}\text { Family } \\
\text { history }\end{array}$ \\
\hline Smoke & 1 & 2 & 4 & 5 \\
Alcohol & $1 / 2$ & 1 & 2 & 6 \\
Obesity & $1 / 4$ & $1 / 2$ & 1 & 4 \\
Family history & $1 / 5$ & $1 / 6$ & $1 / 4$ & 1 \\
$\begin{array}{c}\text { Column sum( } \\
\mathbf{s i}_{\mathbf{i}} \text { ) }\end{array}$ & $\mathbf{1 . 9 5}$ & $\mathbf{3 . 6 6}$ & $\mathbf{7 . 2 5}$ & $\mathbf{1 6}$ \\
\hline
\end{tabular}

$$
\text { A(factors })=\left(\begin{array}{cccc}
1 & 2 & 4 & 5 \\
1 / 2 & 1 & 2 & 6 \\
1 / 4 & 1 / 2 & 1 & 4 \\
1 / 5 & 1 / 6 & 1 / 4 & 1
\end{array}\right)
$$

This sample of data has an information for $n=150$ patients. It contains four factors per person. We have done a questionnaire to the doctors of this hospital in order to construct the pair-wise matrix, based on the odds ratio of these main factors. Table 4, shows the risk factors pair-wise comparisons, for the second level of the hierarchy.

Firstly, we calculate the eigenvalue $\lambda_{\max }$ for this matrix, and the vector of relative weights as follow:

$$
\begin{gathered}
\omega_{1}=\sqrt[4]{1 \cdot 2 \cdot 4 \cdot 5}=2.5 \quad \omega_{2}=\sqrt[4]{\frac{1}{2} \cdot 1 \cdot 2 \cdot 6}=1.56 \\
\omega_{3}=\sqrt[4]{\frac{1}{4} \cdot \frac{1}{2} \cdot 1 \cdot 4}=0.84 \quad \omega_{4}=\sqrt[4]{\frac{1}{5} \cdot \frac{1}{6} \cdot 1 \cdot 4}=0.3 \quad \sum_{i=1,4} \omega_{i}=5.2
\end{gathered}
$$

The normalized vector is:

$$
\omega=\left(\frac{2.5}{5.2}, \frac{1.56}{5.2}, \frac{0.84}{5.2}, \frac{0.3}{5.2}\right)=(0.48,0.3,0.16,0.06)
$$


We denote with vector $s=(1.95,3.6,7.25,16)$ the sum of the columns of the matrix.

$\lambda_{\max }=\sum_{i=1,4} \omega_{i} \cdot s_{i}=0.48 \cdot 1.95+0.3 \cdot 3.6+0.16 \cdot 7.25+0.06 \cdot 16=4.1$.

The matrix is consistent because the eigen-value:

$\lambda_{\max }=4.1 \prec \lambda_{\max }^{*}=4.270$.

Now, we have to construct, for the third level, the pair-wise comparisons for each type of cancer depending on the factors selected. Next we have to find for each table the eigenvector and then rank the results by Table 5 , Table 6 , Table 7 , and Table 8 .

Table 5 Comparison of the cancer types related to smoke factor.

\begin{tabular}{lllll}
\hline Smoke factor & Lung & Prostate & Breast & Throat \\
\hline Lung & 1 & 3 & $1 / 5$ & $1 / 9$ \\
Prostate & $1 / 3$ & 1 & 3 & $1 / 3$ \\
Breast & 5 & $1 / 3$ & 1 & 3 \\
Throat & 9 & 3 & $1 / 3$ & 1 \\
& & & & \\
Column sum & $\mathbf{1 5 . 3 3}$ & $\mathbf{7 . 3 3}$ & $\mathbf{4 . 5 3}$ & $\mathbf{4 . 4 4}$ \\
\hline
\end{tabular}

Table 6 Comparison of the cancer types related to alcohol factor.

\begin{tabular}{lllll}
\hline Alcohol factor & Lung & Prostate & Breast & Throat \\
\hline Lung & 1 & 3 & 7 & 9 \\
Prostate & $1 / 3$ & 1 & 5 & 7 \\
Breast & $1 / 7$ & $1 / 5$ & 1 & 3 \\
Throat & $1 / 9$ & $1 / 7$ & $1 / 3$ & 1 \\
Column sum & $\mathbf{1 . 5 8}$ & $\mathbf{4 . 3 4}$ & $\mathbf{1 3 . 3 3}$ & $\mathbf{2 0}$ \\
\hline
\end{tabular}

Table 7 Comparison of the cancer types related to obesity factor.

\begin{tabular}{lllll}
\hline Obesity factor & Lung & Prostate & Breast & Throat \\
\hline Lung & 1 & 3 & $1 / 4$ & 2 \\
Prostate & $1 / 3$ & 1 & $1 / 7$ & 2 \\
Breast & 4 & 7 & 1 & 6 \\
Throat & $1 / 2$ & $1 / 2$ & $1 / 6$ & 1 \\
Column sum & $\mathbf{5 . 8 3}$ & $\mathbf{1 1 . 5}$ & $\mathbf{1 . 4}$ & $\mathbf{1 1}$ \\
\hline
\end{tabular}

Table 8 Comparison of the cancer types related to family history factor.

\begin{tabular}{lllll}
\hline $\begin{array}{c}\text { Family history } \\
\text { factor }\end{array}$ & Lung & Prostate & Breast & Throat \\
\hline Lung & 1 & 4 & 6 & 7 \\
Prostate & $1 / 4$ & 1 & 3 & 4 \\
Breast & $1 / 6$ & $1 / 3$ & 1 & 2 \\
Throat & $1 / 7$ & $1 / 4$ & $1 / 2$ & 1 \\
Column sum & $\mathbf{1 . 5 5}$ & $\mathbf{5 . 5 8}$ & $\mathbf{1 0 . 5}$ & $\mathbf{1 4}$ \\
\hline
\end{tabular}

Table 9 Local weights for every table above. 


\begin{tabular}{|c|c|c|c|c|}
\hline & $\lambda_{\max }$ & \multicolumn{3}{|c|}{$\omega($ vector $)$} \\
\hline Tab 5 & 3.96 & \multicolumn{3}{|c|}{$\omega($ lung $)=(0.11,0.16,0.33,0.38)$} \\
\hline Tab 6 & 4.26 & \multicolumn{3}{|c|}{$\omega($ prostate $)=(0.58,0.29,0.085,0.04)$} \\
\hline Tab 7 & 3.8 & \multicolumn{3}{|c|}{$\omega($ breast $)=(0.19,0.096,0.63,0.078)$} \\
\hline Tab 8 & 3.9 & \multicolumn{3}{|c|}{$\omega($ throat $)=(0.61,0.22,0.09,0.06)$} \\
\hline Tab 4 & 4.1 & \multicolumn{3}{|c|}{$\omega($ factor $)=(0.48,0.3,0.16,0.06)$} \\
\hline wbre & wthro & $\omega$ factor & result & Rankin \\
\hline 0.19 & $0.61)$ & $(0.48)$ & $(0.286)$ & $(1)$ \\
\hline 0.096 & 0.22 & 0.3 & 0.185 & 4 \\
\hline 0.63 & 0.09 & 0.16 & 0.280 & 2 \\
\hline 0.078 & 0.06 & $(0.06)$ & 0.207 & $(3)$ \\
\hline
\end{tabular}

This gives a final priority of 0.285 for lung cancer, 0.185 for prostate cancer, 0.280 for breast cancer and 0.207 for throat cancer.

\section{Conclusion}

We have classified the cancer types, by the factors included in level 2, using the pair-wise comparison method of AHP. The AHP methodology applied to the data collected from Tirana Hospital, shows that lung cancer is mostly spread in humans with the highest risk, and prostate cancer is the least spread in humans, with the smallest risk. The model chosen is a method for helping the decision maker to the problem that has a limited number of choices, with a limited number of factors at each choice.

\section{Acknowledgments}

This work is part of my doctoral study research at the University of Tirana, Faculty of Natural Sciences, Department of Applied Mathematics. We acknowledge financial support from the University “Aleksander Moisiu” Durres.

\section{References}

1. R.W.Saaty, The Analytic Hierarchy Process-What is and how it is used, math modeling, Vol 9, No 3,4,5,1987, 161-176.

2. L.Abdullah, I.Taib, R.Salleh, Public perceptions of cancer risk using Analytic Hierarchy Process , Journal of applied sciences, volume 12, nr 9, 2009, p 2319-2324.

3. Calle, E.E. and M.J.Thun, 2004. Obesity and cancer , 23; 6365-6378.

4. Liana Najib, Lazim Abdullah, Ilyani Abdullah, Zabidin Salleh, Weights of road accidents causes using Analytic Hierarchy Process, ARPN Journal of Science and Technology, vol 2, nr 2, 39-44, 2012.

5. Dyer, J.S, 1990b, A clarification of remarks on the Analytic Hierarchy Process. Manage. Sci 36, 274-276. 
International Conference on Computer Science and Communication Engineering, Nov 2015

6. Kim,S.E, E.J.Perez-Stable, S. Wong, S. Gregorich, G.F.Sawaya, J.M.E Walshand C.P.Kaplan 2008, Association between cancer risk perception and screening behavior among diverse woman. Arch.Int.Med, 168, 30-700.

7. Kamal. Al-Subhi Al-Harbi, Application of the AHP in project management, International Journal of Project Management 19, 2001. 